\title{
Dioxins in the Food Chain: Contamination Fingerprint Analysis in Breeding Hens, Hatching Eggs and Broilers
}

\author{
Miguel Oliveira Cardo ${ }^{1}$, Marta Castel-Branco르, Valeska Andreozzi², \\ Fernando Almeida Bernardo ${ }^{1}$ \\ ${ }^{1}$ Faculty of Veterinary Medicine, University of Lisbon (FMV/UL), Lisbon, Portugal \\ ${ }^{2}$ Center of Statistics and Applications of University of Lisbon (CEAUL), Lisbon, Portugal \\ Email: m.o.cardo@mail.telepac.pt
}

Received 20 August 2014; revised 16 September 2014; accepted 12 October 2014

Copyright (C) 2014 by authors and Scientific Research Publishing Inc.

This work is licensed under the Creative Commons Attribution International License (CC BY). http://creativecommons.org/licenses/by/4.0/

(c) (†) Open Access

\begin{abstract}
While routine monitoring poultry meat was obtained from breeding hens, dioxins contaminations were detected in Portugal. Levels of 430.9 pg PCDD/F-WHO-TEQ/g1 were found, which are higher than the official limits legally allowed for this matrix (1.75 pg PCDD/F-WHO-TEQ/g). To identify the magnitude of the contaminations, 60 samples were collected from poultry farms and different matrices, namely: feed, water, wood shavings from the litters, muscle of the breeding hens, hatching eggs collected in the positive farm and muscle collected from broilers farms supplied by the positive breeding farm. The comparison of the dioxins congeners profiles showed that there was a coincidence of peaks of higher relative concentrations in the wood shavings, with the peaks of the highest relative concentration in the hatching eggs, especially the relative concentrations of the congeners 1,2,3,4,6,7,8-HpCDD and OCDD, which may be explained by the role of VLDLy in the delivery of triglycerides to the oocyte, where they will be used as the energy source for the developing embryo. The comparison of the dioxins congeners profiles of the breeding hens muscle with the poultry muscle, showed a coincidence of peaks of higher relative concentrations in the congeners 1,2,3,7,8-PeCDD, 1,2,3,6,7,8-HxCDD, 1,2,3,4,6,7,8-HpCDD and OCDD which may indicate a dechlorination pathway "in vivo". Results allowed concluding that those wood shavings, improperly used as poultry litters, were certainly the source of contamination of the food chain.
\end{abstract}

\section{Keywords}

Dioxin Fingerprint, Food Chain, Poultry

\footnotetext{
${ }^{1}$ The abbreviation "PCDD/F-WHO-TEQ” refers to the toxic equivalence factors (TEF) established for a range of PCDDs and PCDFs by the World Health Organization (WHO).

How to cite this paper: Cardo, M.O., Castel-Branco, M., Andreozzi, V. and Bernardo, F.A. (2014) Dioxins in the Food Chain: Contamination Fingerprint Analysis in Breeding Hens, Hatching Eggs and Broilers. Journal of Environmental Protection, 5, 1323-1330. http://dx.doi.org/10.4236/jep.2014.513126
} 


\section{Introduction}

Food chain safety has been sporadically stressed by the presence of chemical hazards as contaminants of many food matrices. Among these hazards, PCDD, PCDF and PCBs are certainly those of the highest concern because of their high social and economic negative impacts. In the last decade many episodes of food chain contamination with dioxins have been reported in European Union [1] [2]. In Portugal, during 2008, an episode of a natural poultry meat contamination with dioxins was also reported [3].

Many sources have been incriminated as vehicles for dioxins to food of animal origin: commercial organic feed, noncommercial feedstuffs, soil, plants, worms and insects [1]. These are the matrices where original contaminations are systemically searched when some animal production is found carrying higher dioxins contaminations. However, in intensive poultry production, the birds do not assess soil or invertebrates. Some hens are accommodated in cages (laying hens) or inside pavilions without soil contact. And when, in these circumstances, feed is also confirmed as dioxin free, other sources must be searched to manage the risk efficiently.

This study concerns to a search performed precisely to determine the source of dioxins contamination found in poultry meat obtained from breeding hens, in its hatching eggs and respective chickens.

\section{Material and Methods}

\subsection{Sampling}

Sampling has been conducted according to following sequence:

- From all possible sources of contamination in the breeding hens positive farm (feed, water and wood chips from litters);

- From hatching eggs laid by the positive breeding hens;

- From the broilers hatched from the eggs laid by the positive breeding hens.

Samples partition was the following: 17 samples of muscle fat were collected from four breeding hen's new batches of the implicated farm; wood shavings from the bedding material $(n=4)$, hatching eggs $(n=3)$, feed $(n$ $=3)$ and water $(\mathrm{n}=3)$.

From the 20 broiler farms supplied with one day old chicks coming from the positive breeding farm, were also sampled (30 samples: $\mathrm{n}=28$ broilers muscle fat and $\mathrm{n}=2$ wood shavings).

Additionally, two positive samples of wood shavings were also tested for detection and quantification of pentachlorophenol-a wood preservative-using extraction with acetone/10\% $\mathrm{H}_{2} \mathrm{SO}_{4}$ under reflux, clean-up with celite/ $\mathrm{H}_{2} \mathrm{SO}_{4}$ column.

The sample storage and transportation were made according good laboratory practices, to ensure sample stability and integrity, avoiding any change that could affect the reliability of the analytical procedure. Each sample was individually identified and packed immediately after collection.

Litter samples were preserved in dry and dark conditions in a cool place, while muscle samples were frozen.

\subsection{Analytical Method}

The analytical method used for detection and quantification of dioxin was the USA EPA method 1613 revision B [4]. This method was developed by the Environmental Protection Agency, Science and Technology of the United States for the determination of 2,3,7,8-CDDs/CDFS replaced through octa-chlorination, dibenzo-p-dioxins and dibenzofurans in aqueous matrices, solid or tissue by isotope dilution, followed by capillary column of high resolution gas chromatography (HRGC)—-high resolution, mass spectrometry (HRMS).

\subsection{Statistical Analysis}

Analysis of data was carried out in accordance with the methodology of the USA EPA, for analysis of contaminants [5].

The methodology is summarized in four basic steps.

Step One: Standardization-the concentration of congeners observed for each sample is standardized. The constituents of each sample are converted to a decimal percentage of the sum of congeners.

Step Two: Construction of the bar plot of the standard concentrations-graphic representation of the standard concentration of the different congeners for each sample. The Y-axis of the bar plot represents the relative amount of each congener in the sample (standard concentration) and in the X-axis it is represented the identifi- 
cation of the 17 different congeners. This chart will give an indication of the congeners that are present in greater concentration and if that pattern is maintained for the different samples.

Step Three: Statistical assessment of pattern reproducibility-this step concerns the used of the square of the Pearson correlation coefficient $\left(\mathrm{r}^{2}\right)$ as a measure to assess whether the profile of the concentration of congeners in the samples (compared visually on the bar plot) is statistically similar.

The Pearson correlation coefficient (r) measures the degree and direction of the correlation (positive and negative) between two variables of metric scale [6].

Thus, a table is generated with the values of $\mathrm{r}^{2}$, in which each sample is compared with all others. If all values of the square of the Pearson correlation coefficient are near 1, it can be stated that the pattern of the samples, compared in pairs, is very similar.

In order to assess the similarity of the concentration of congeners profile in various samples, it was used the global average comparison which is defined as the average values of $r^{2}$ found. It is considered that the profiles are similar if the average of $r^{2}$ is close to 1 and the standard deviation (SD) is next to zero.

Step Four: Evaluation of the source of contamination-once established the congener's profile of the dioxins contaminations in each group of samples (litters, breeding hens, hatching eggs and broilers), the same methodology of the previous steps was applied to investigate a possible association between them.

\section{Results}

A total of 17 samples were found positive in the 60 samples collected: 3 wood shavings, 4 breeding hens muscle fat, 3 hatching eggs and 7 broilers muscle fat. All samples of feed and drinking water were negative.

The higher WHO-TEQ levels of PCDDs and PCDFs contaminations were detected in breeding hens muscle fat (430.9 pg WHO-TEQ/g) with an average of $193.66 \mathrm{pg}$ WHO-TEQ/g. The higher level of dioxins found in the positive wood shavings samples was $65.94 \mathrm{pg}$ WHO-TEQ/g with an average of $38.85 \mathrm{pg}$ WHO-TEQ/g. The higher level of dioxins found in the positive hatching eggs samples was $61.33 \mathrm{pg}$ WHO-TEQ/g with an average of $42.25 \mathrm{pg}$ WHO-TEQ/g. The higher level of dioxins found in the positive broiler muscle fat samples was 8.59 pg WHO-TEQ/g with an average of $4.67 \mathrm{pg}$ WHO-TEQ/g (Figure 1).

The two wood shavings samples tested for detection and quantification of pentachlorophenol, revealed a concentration of 1.1 and $2.0 \mathrm{mg} / \mathrm{kg}$ of the product.

The square of the Pearson correlation coefficient $\left(\mathrm{r}^{2}\right)$ and standard deviation (sd) of the different congeners relative concentrations within each group of analysis is considerable: $\mathrm{r}^{2}=0.99$ and sd $=0.01$ for the litters, $\mathrm{r}^{2}=$ 0.75 and $s d=0.15$ for the breeding hens, $r^{2}=1$ and $s d=0$ for the hatching eggs and $r^{2}=0.83$ and $s d=0.11$ for the broilers.

The square of the Pearson correlation coefficient $\left(\mathrm{r}^{2}\right)$ and standard deviation (sd) of the different congeners relative concentrations between each group of analysis is not so strong:

$r^{2}=0.54$ and $s d=0.16$ for the wood shavings versus breeding hens (Figure 2);

$r^{2}=0.58$ and $s d=0.02$ for the breeding hens versus hatching eggs (Figure 3);

$r^{2}=0.72$ and $s d=0.16$ for the hatching eggs versus broilers (Figure 4).

The square of the Pearson correlation coefficient $\left(\mathrm{r}^{2}\right)$ and standard deviation (sd) of the different congeners relative concentrations between breeding hens and broilers muscle fat $\left(r^{2}=0.8\right.$ and sd $\left.=0.12\right)$ is very high (Figure 5), as well as between litters and hatching eggs $\left(r^{2}=0.72\right.$ and $\left.s d=0.16\right)$ (Figure 6).

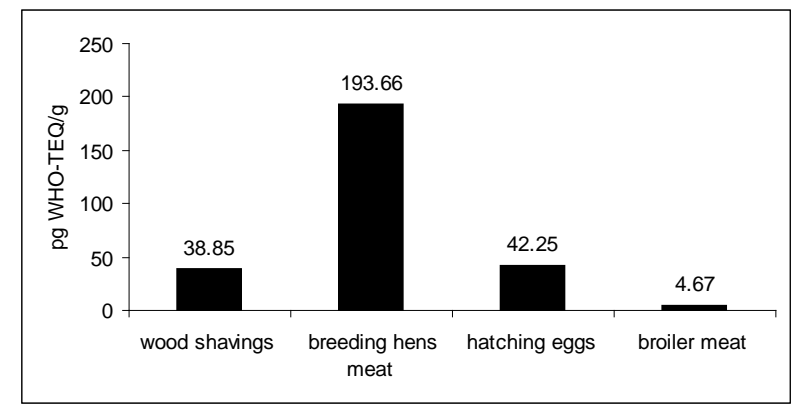

Figure 1. Average levels of dioxins found in positive samples. 


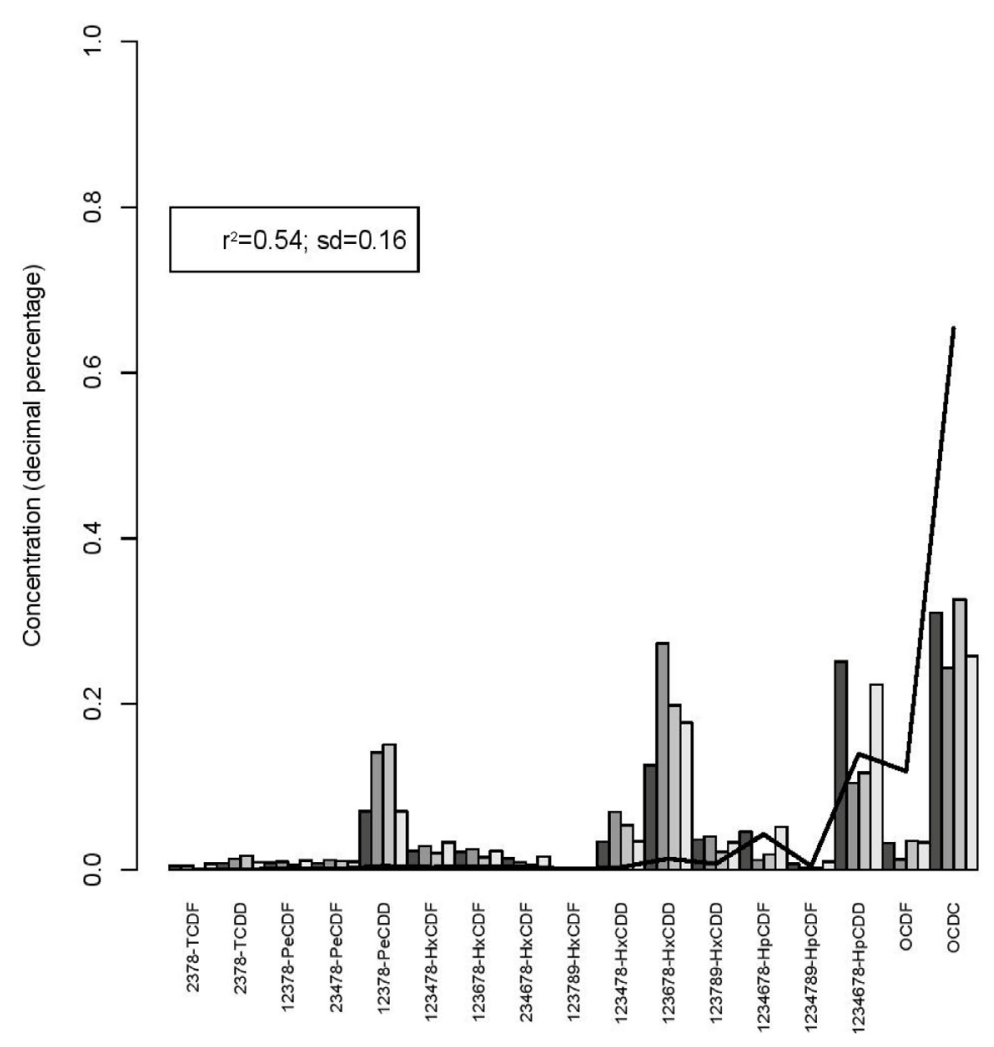

Figure 2. Wood shavings from bedding material (line) vs breeding hens.

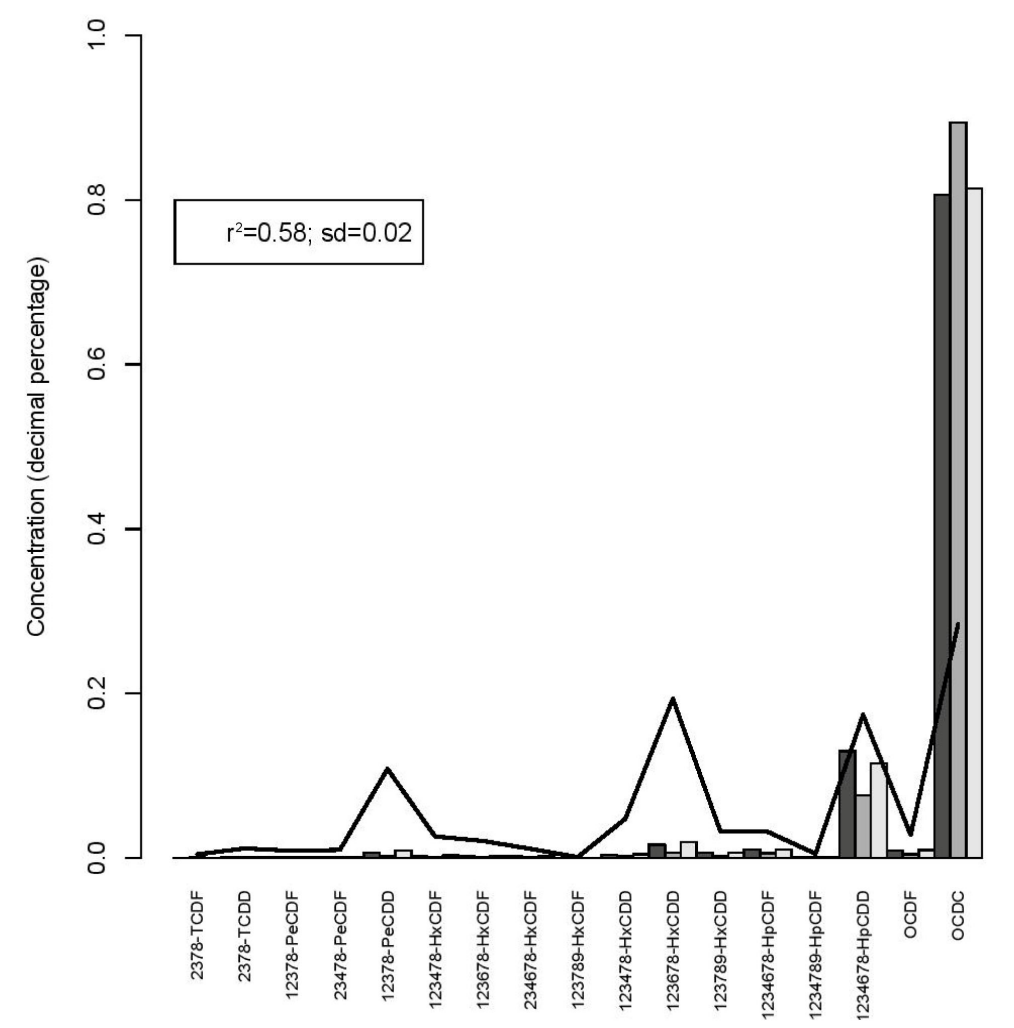

Figure 3. Breeding hens (line) vs hatching eggs. 


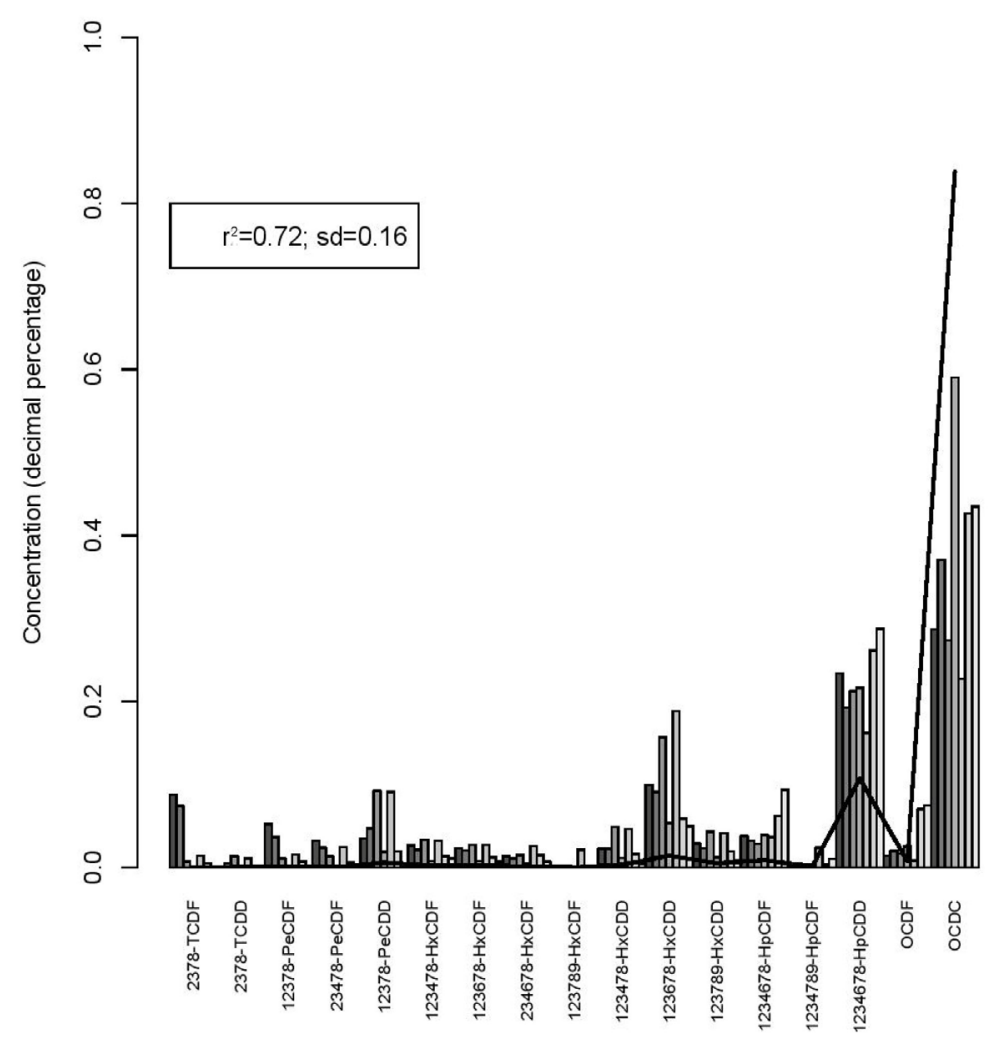

Figure 4. Hatching eggs (line) vs broilers.

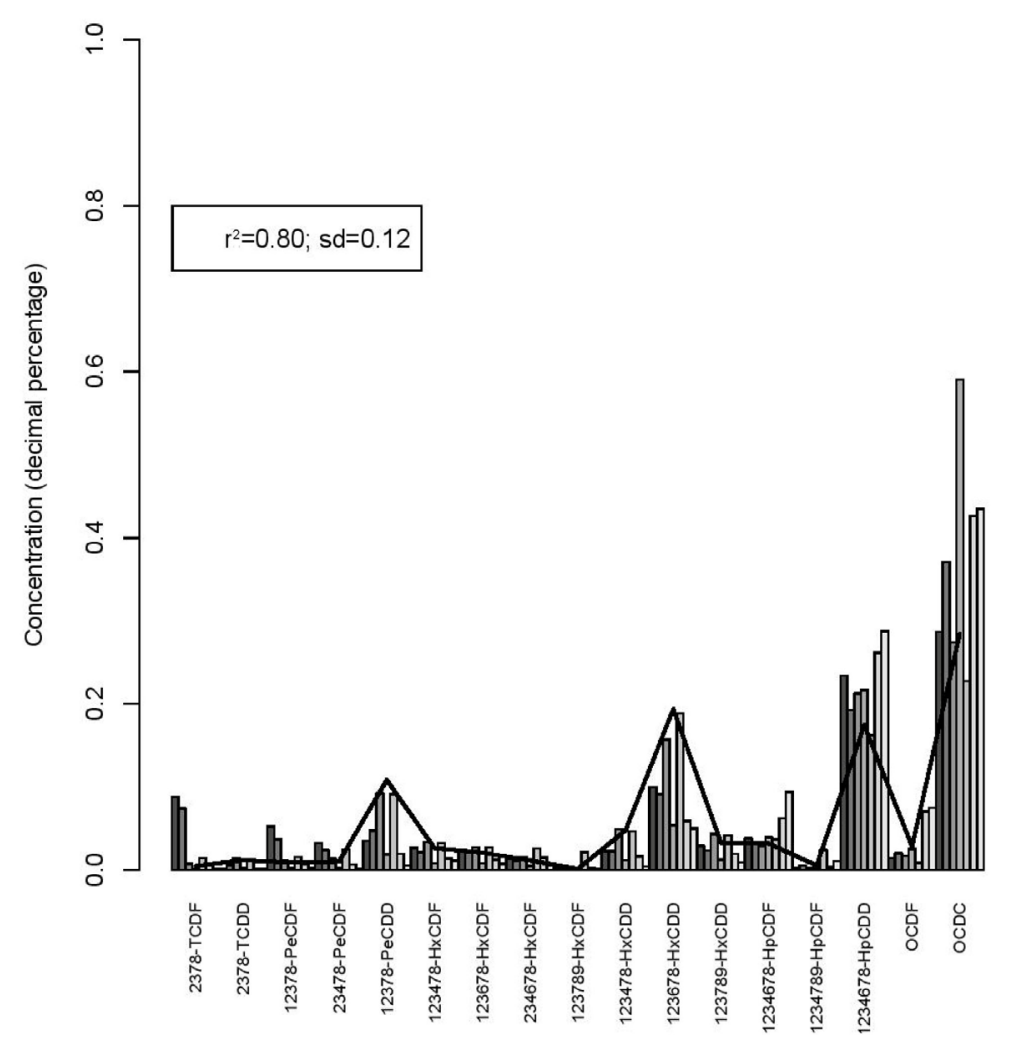

Figure 5. Hatching eggs (line) vs broilers. 


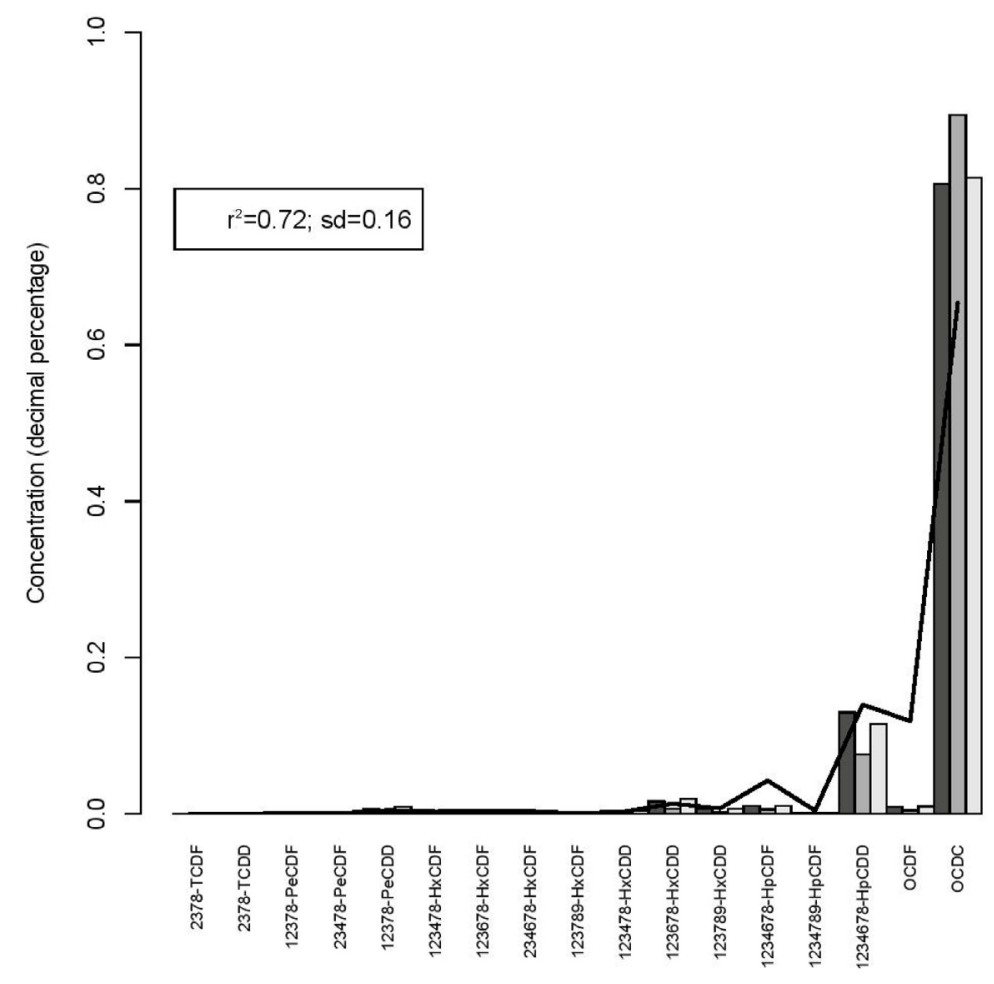

Figure 6. Wood shavings from bedding material (line) vs hatching eggs.

\section{Discussion}

The results set showed considerable high contaminations of the wood shavings, indicating that these materials are the likely source of contamination of the animals.

During the earlier stages of its development, chicks have as habit to eat some particles of bedding materials. That behavior is hazardous potentiated due to the fact that they select some special fragments with darker points, because they mimic the image of the small arthropods that are usually eaten in natural conditions (instinctive behavior). Some wood by-product, obtained from partial burned pines, frequently have these different color points.

The pattern detected in the wood shavings matches with the profile found for contaminated technical pentachlorophenol by other authors [7]-[9]; this suggests that the wood shavings used in the litters were obtained from treated wood, being the wood preservative the possible source.

The assessment carried out between the profiles found in each of the wood shavings samples and the muscle fat of the breeding hens reared on those litters; the hatching eggs laid by those contaminated hens and the respective hatched chicks showed a coincidence of peaks of higher relative concentration in its samples, concerning especially to the relative concentrations of the congeners 1,2,3,4,6,7,8-HpCDD and OCDD.

Graphic representation of the relative concentrations of the different dioxin congeners in each matrices had different comparative expressions. For example, in the broilers and breeding hens muscle fat profiles, the average relative concentration of OCDD was 52\% and 53\% lower, comparatively to the wood shavings and hatching eggs profile, respectively [10]. On the other hand, the average relative concentration of 1,2,3,7,8-PeCDD, $1,2,3,6,7,8-\mathrm{HxCDD}$ and 1,2,3,4,6,7,8-HpCDD in the broilers and breeding hens muscle fat profiles was $50 \%$ $97 \%$ higher when compared with the litters and hatching eggs profiles.

The figures suggest that, probably, there was some factor that may affect the consistency in quantitative terms of the relative concentration of congeners found in wood shavings and in poultry muscle fat. Many explanations can be pointed to these facts, like: an "in vivo", metabolic pathway (dechlorination of the most chlorinated congeners); a differentiation on the lipophilic affinity of each congener; variations on the affinity to the Ah receptor and selective faecal excretion by the birds, also equivalent to a lower absorptive capacity [11]-[13].

It was verified an equilibrium between the dioxin concentration in the contaminant ingested by chickens 
(38.85 pg WHO-TEQ/g) and the dioxin concentration in the eggs (42.25 pg WHO-TEQ/g), which is confirmed by other study [1] [14]. The fact that the square of the Pearson correlation coefficient $\left(r^{2}\right)$ of the different congeners relative concentrations between litters and hatching eggs $\left(r^{2}=0.72\right.$ and $\left.s d=0.16\right)$ and the graphic representations of the profiles was so consistent, may be explained by the estrogens produced during egg production which stimulate the liver to produce the egg-yolk targeted, very-low density lipoprotein (VLDLy). This oestrogen-dependent shift in VLDL synthesis from the production of generic VLDL, which ranges in size from 30 to $>200 \mathrm{~nm}$, to smaller, yolk-targeted VLDL, which ranges in diameter from 15 to $55 \mathrm{~nm}$ represents a dramatic shift in lipid metabolism associated with changes in the composition and structure of VLDL in egg-producing females. Whereas the role of generic VLDL is to transport triglycerides throughout the body for tissue utilization or storage in adipose tissue, the function of VLDLy is to deliver triglycerides to the oocyte, where they will be used as the energy source for the developing embryo. The smaller diameter of VLDLy is thought to be critical for enabling the particles to pass through the pores in the granulosa basal lamina of the ovary, allowing them access to the developing ovarian follicles. VLDLy particles are in high plasma concentrations in laying hens and are resistant to hydrolysis by extra-ovarian tissues which preserves the triglycerol-rich VLDLy for uptake by the developing ovarian follicles [10].

\section{Conclusions}

This study clearly identified the source of the poultry contamination, attending to the relationship established with an environmental vehicle of dioxins (wood shavings). This achievement is based on the consistence of the results obtained with all the tested materials regarded as potential source and the fingerprint analysis of the relative concentration of the 17 dioxin congeners.

It can be stated that unusual sources of food chain contamination with dioxins must be always put in perspective when the incident is not affiliated in the most common sources.

\section{Acknowledgements}

The authors grateful acknowledge Food and Veterinary General Directorate, the Portuguese food and veterinary competent authority, for granting permission to use the data.

Andreozzi, V. collaboration was supported by FCT projects PTCD/MAT/118335/2010 and FCT-Pest-OE/ MAT/UI0006/2011 and Castel-Branco, M. collaboration was supported by FCT-Pest-OE/MAT/UI0006/2011.

\section{References}

[1] De Vries, M., Kwakkel, R. and Kijlstra, A. (2006) Dioxins in Organic Eggs: A Review. Wageningen Journal of Life Sciences, 54, 207-221. http://dx.doi.org/10.1016/S1573-5214(06)80023-0

[2] Kennedy, J., Delaney, L., McGloin, A., Hudson, E. and Wall, P. (2010) Public Perceptions of the Dioxin Crisis in Irish Pork. http://www.ucd.ie/geary/static/publications/workingpapers/gearywp200919.pdf

[3] Cardo, M., Félix, V. and Bernardo, F. (2009) Dioxins in Poultry Products: A Case Study. Journal of Veterinary Pharmacology and Therapeutics, 32, 95.

[4] United States Environment Protection Agency (1994) Method 1613 Revision B-Tetra-Through Octa-Chlorinated Dioxins and Furans by Isotope Dilution HRGC/HRMS. United States Environment Protection Agency, Washington DC, 89.

[5] Russell, H. and Plumb, J. (2004) Fingerprint Analysis of Contaminant Data: A Forensic Tool for Evaluating Environmental Contamination. National Exposure Research Laboratory Environmental Sciences Division, Las Vegas, 27.

[6] Johnson, R. and Wichern, D. (2001) Applied Multivariate Statistical Analysis. Englewood Cliffs, New Jersey. 5th Edition, Prentice Hall, Upper Saddle River, 761.

[7] Hagenmaier, H. and Brunner, H. (1987) Isomer Specific Analysis of Pentachlorophenol and Sodium Pentachlorophenate for 2,3,7,8-Substituted PCDD and PCDF at Sub-PPB Levels. Chemosphere, 16, 1759-1764. http://dx.doi.org/10.1016/0045-6535(87)90164-0

[8] Fries, G.F., Feil, V. and Davison, K. (1996) The Significance of Pentachlorophenol-Treated Wood as a Source of Dioxin Residues in United States Beef. Organohalogen Compounds, 28, 156-159.

[9] Cleverly, D., Schaum, J., Schweer, G., Becker, J. and Winters, D. (1997) The Congener Profiles of Anthropogenic Sources of Chlorinated Dibenzo-p-Dioxins and Chlorinated Dibenzofurans in the United States. The 17th International Symposium on Chlorinated Dioxins and Related Compounds, Indianapolis, 25-29 August 1997, 430-435. 
[10] Salvantem, K., Lin, G., Rosemary L., Walzem, R. and Williams, T. (2007) Characterization of Very-Low Density Lipoprotein Particle Diameter Dynamics in Relation to Egg Production in a Passerine Bird. Journal of Experimental Biology, 210, 1064-1074. http://dx.doi.org/10.1242/jeb.02724

[11] Lynam, M., Kuty, M., Damborsky, J., Koca, J. and Adriaens, P. (1998) Molecular Orbital Calculations to Describe Microbial Reductive Dechlorination of Polychlorinated Dioxins. Environmental Toxicology and Chemistry, 17, 988997. http://dx.doi.org/10.1002/etc.5620170603

[12] Huwe, J., Feil, V., Zaylskie, R. and Tiernan, T. (2000) An Investigation of the in Vivo Formation of Octachlorodibenzo-p-Dioxin. Chemosphere, 40, 957-962. http://dx.doi.org/10.1016/S0045-6535(99)00339-2

[13] Pirard, C. and Pauw, E. (2004) Uptake of Polychlorodibenzo-p-Dioxins, Polychloro-Dibenzofurans and Coplanar Polychloro-Biphenyls in Chickens. University of Liège, Liège, Belgium. Environment International, 31, 585-591. http://dx.doi.org/10.1016/j.envint.2004.10.008

[14] Petreas, M., Goldman, L., Hayward, D., Chang, R., Flattery, J., Wiesmüller, T. and Stephens, R. (1991) Biotransfer and Bioaccumulation of PCDD/PCDFs from Soil: Controlled Exposure Studies of Chickens. Chemosphere, 23, 1731-1741. http://dx.doi.org/10.1016/0045-6535(91)90021-5 
Scientific Research Publishing (SCIRP) is one of the largest Open Access journal publishers. It is currently publishing more than 200 open access, online, peer-reviewed journals covering a wide range of academic disciplines. SCIRP serves the worldwide academic communities and contributes to the progress and application of science with its publication.

Other selected journals from SCIRP are listed as below. Submit your manuscript to us via either submit@scirp.org or Online Submission Portal.
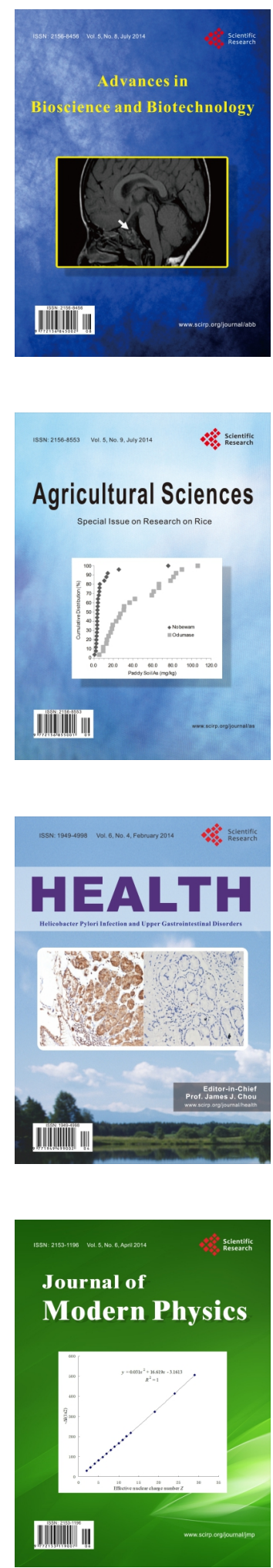
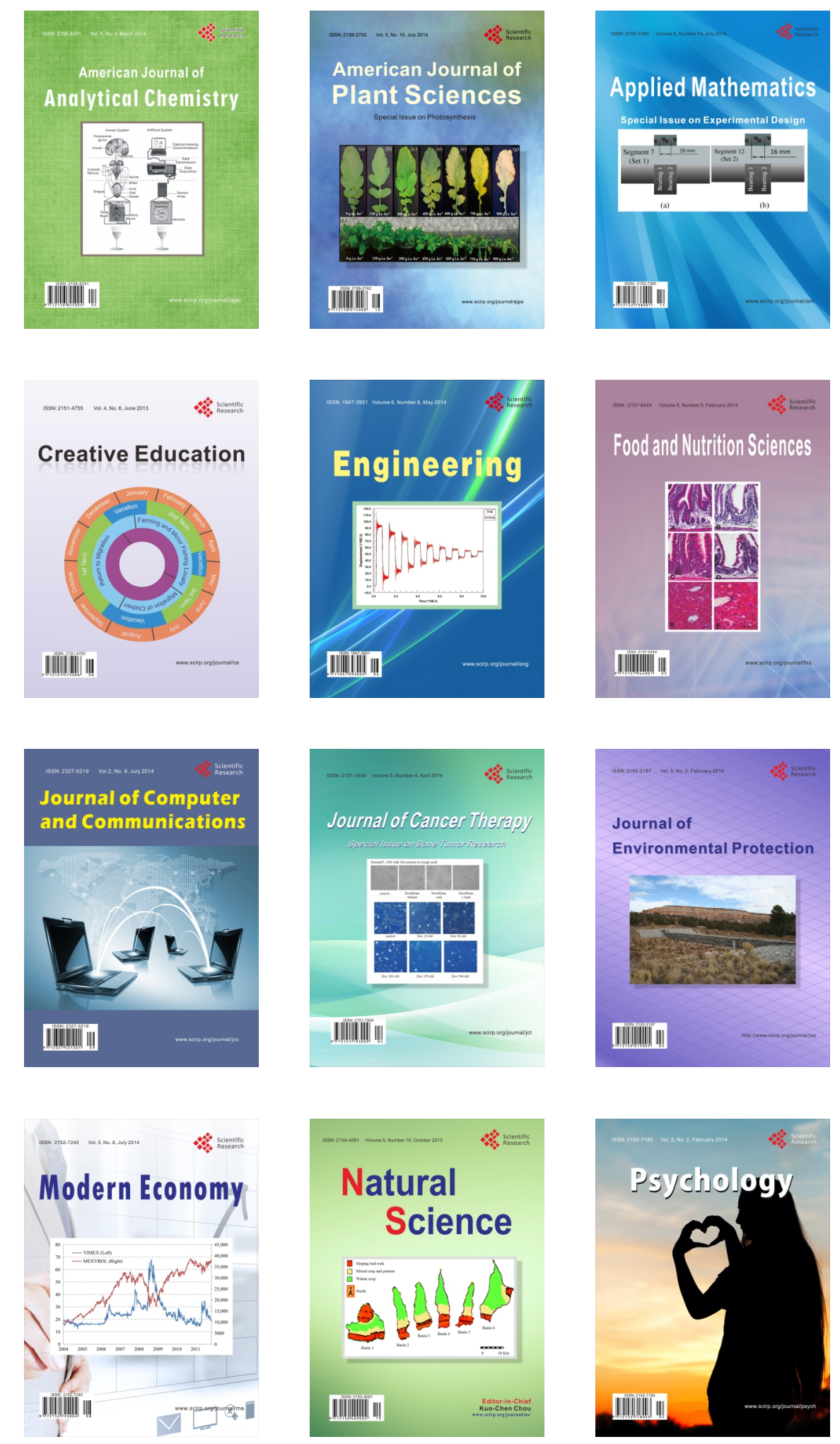